\title{
Maximum Penetration of Distributed Generations and Improvement of Technical Indicators in Distribution Systems
}

\author{
Thuan Thanh Nguyen (D), ${ }^{1}$ Thang Trung Nguyen $\mathbb{D}^{2}{ }^{2}$ and Ngoc Au Nguyen $\mathbb{D}^{3}$ \\ ${ }^{1}$ Faculty of Electrical Engineering Technology, Industrial University of Ho Chi Minh City, Ho Chi Minh City, Vietnam \\ ${ }^{2}$ Power System Optimization Research Group, Faculty of Electrical and Electronics Engineering, Ton Duc Thang University, \\ Ho Chi Minh City, Vietnam \\ ${ }^{3}$ Faculty of Electrical and Electronics Engineering, Ho Chi Minh City University of Technology and Education, \\ Ho Chi Minh City, Vietnam
}

Correspondence should be addressed to Thang Trung Nguyen; nguyentrungthang@tdtu.edu.vn

Received 29 August 2020; Revised 6 December 2020; Accepted 17 December 2020; Published 30 December 2020

Academic Editor: Gordon Huang

Copyright (c) 2020 Thuan Thanh Nguyen et al. This is an open access article distributed under the Creative Commons Attribution License, which permits unrestricted use, distribution, and reproduction in any medium, provided the original work is properly cited.

\begin{abstract}
Increasing the possible capacity of distributed generations (DGs) supplying to distribution system (DS) is a highly effective solution to attract the investment of distributed generation (DG) installation in the DS. However, the presence of DGs will affect the technical indicators of the DS. This paper determines solutions of the DG placement problem for maximizing the size of distributed generations (DGs) and improving the technical indicators consisting of power loss reduction, increasing of balance among feeders and balance among branches, and voltage deviation reduction. A max-min method is proposed to combine the membership objective functions. The location and size of DGs are optimized based on an improved cuckoo search algorithm (ICSA). The simulation results for the 84-node system show that the proposed multiobjective problem not only helps to increase the capacity of DGs but also improves the technical factors. Moreover, the DG's uncertainty is also validated to show its negative impacts on the technical indicators of the DS. Furthermore, ICSA is worthy for finding the optimal solution for the DG placement problem.
\end{abstract}

\section{Introduction}

DG is small power sources that are connected directly to the DS $[1,2]$. The definition of DG based on its size is a little different among different countries as well as organizations $[2,3]$, but in general, it can be classified into categories as micro DGs with rating less than $5 \mathrm{~kW}$, small DGs with rating from $5 \mathrm{~kW}$ to smaller than $5 \mathrm{MW}$, medium DGs with rating from $5 \mathrm{MW}$ to smaller than $50 \mathrm{MW}$, and large DGs with rating from 50 to $300 \mathrm{MW}[2,4]$. The benefits related to economic, technical, and environmental obtained by installing of DGs in the distribution systems are remarkable [5]. Thus, the DG placement problem has attracted the attention of the researchers.

One of the biggest technical benefits of DG installation on the DS is to decrease power loss. In addition, because of operating at low voltage level, power loss of the DS always takes a higher portion compared to other parts of the power system. Thus, as installation of DGs on the distribution system, power loss reduction is one of the most concerned objectives. In [6], location and size of DGs are optimized for loss reduction based on genetic algorithm (GA). In [7], binary particle swarm optimization is presented to find the optimal location and size of photovoltaic for loss reduction in the DS. In [8], stud krill herd algorithm is employed for optimizing DG installation in the DS for minimizing the losses. Similar to the above studies, the DG installation in the DS for loss reduction is also addressed in [9-15].

However, installing of DG on the DS affects not only power loss but also other technical factors. Therefore, some studies have focused on solving the DG placement problem to satisfy the multigoal function. In [16], the multigoal function for DG placement consisting of power loss, operational cost, and voltage deviation reduction is considered 
based on the invasive weed algorithm. In [17], backtracking search algorithm is presented for the DG installation problem for losses reduction and voltage profile enhancing. In [18], the multigoal function for DG placement consisting of power losses, voltage stability, and voltage profile indexes is solved based on the quasioppositional teaching learning algorithm. The location and size of DGs are determined to enhance the transient stability factor and voltage and decrease losses in [19]. In [20], power loss, voltage profile, load balancing, and voltage stability indexes are the membership functions considered for optimizing location and size of DGs in the DS.

In terms of solving technique for the DG placement problems, there are two major method groups consisting of the classical optimization methods, such as linear programming [21], mixed integer [22, 23], and dynamic programming [24], and the metaheuristic methods comprising of GA [6], particle swarm optimization [7], honey bee mating optimization [25], cuckoo search [26], runner root algorithm [27], Salp swarm algorithm [28], etc., in which, the first method group proved to be more disadvantaged when compared to the latter group in aspects of quality of obtained solution and handling constraints for the problem.

Cuckoo search algorithm (CSA) belongs to the second group method aforementioned. The CSA was inspired by the generative strategy of cuckoo birds [29]. Since being proposed, CSA has been being used for many optimal problems in different fields [30] and in the power system field $[26,31-33]$. In addition, to improve the efficiency of the CSA, a lot of improved versions of CSA have been proposed [34-37], in which, the improved cuckoo search algorithm (ICSA) in [37] is a recent improved version of CSA that has been successfully proposed for a problem related to operation of the distribution system. Moreover, ICSA has demonstrated a better performance compared to CSA. In ICSA, the new local search strategy is used for exploiting the better solution nearby the so-far best solution beside the searching strategies of the original CSA.

Vietnam is located on the equatorial line and has a long coastline, which results in a lot of sunshine and wind resources. In recent years, with many positive policies for the development of renewable energy sources, many electricity sources related to renewable energy such as photovoltaic and wind generations have been built and connected to the electricity system. However, most of them are built with large-capacity, centralized power generation and linked to the transmission system. The small-capacity sources connected to the DS are still very limited. One of the reasons for this situation is that the investment cost per unit of capacity for small DGs connected to distribution system is higher than that of large DGs connected to the transmission system. Therefore, increasing the possible capacity of DGs pumped into the distribution system is one of the solutions to attract investment of small DGs installation in the distribution systems. Increasing DG capacity pumped to the DS will undoubtedly affect the technical factors of the system such as load balancing, power loss, nodes' voltage, and branches' current. Thus, it is essential to address the problem of DG placement under multiobjective perspective.
This paper presents the DG placement problem for maximizing the size of DGs pumped to the DS and improving the technical indicators related to operating the distribution system comprising of power loss reduction, increase of balance among feeders, and balance among branches and voltage deviation reduction. The fuzzy technique based on the max-min method is proposed to combine the membership objective functions. In order to search the optimal size and location of DGs, ICSA is adapted to solve the problem. The calculated results for the 84-node practical distribution system show that the proposed multiobjective DG placement problem not only helps to increase the DGs' capacity but it also improves the technical factors of the system. In terms of solving method, ICSA is one of the efficient methods for searching location and size of DGs to satisfy the multiobjective as well as other goals. The main highlights of this work can be recapitulated as follows:

(i) The problem of optimizing location and size of DGs is addressed in terms of maximizing DGs' capacity pumped to distribution system and improving the technical indicators of the system

(ii) The max-min technique is proposed for choosing the final solution for the membership objective functions

(iii) The ICSA is adapted to optimize the location and size of DGs in the DS

(iv) The proposed problem and ICSA method are evaluated on the 84-node practical distribution system

(v) The multiobjective problem helps to gain more DGs' capacity and improvement of technical indicators compared to the case of no DGs placement and the single-objective problems

(vi) The comparisons of ICSA with other methods in the literature present the reliability of ICSA for the DG placement problem

\section{Problem Formulation of DG Placement}

In this work, the DG placement problem in the DS is considered to satisfy five objective functions consisting of power loss reduction, increasing balance among feeders as well as among branches, increasing the sum of capacity of DGs connected to the DS, and deviation voltage reduction. The details of the membership functions are demonstrated as follows.

2.1. Reduce Power Loss (PL). Because of low voltage level and high current of the DS, its power loss usually takes a high portion in the power system's losses. DG installation is one of the efficient methods for power loss reduction. The first goal function considered is to reduce the power loss of the DS that is presented as follows:

$$
\min f_{1}=\sum P_{\text {loss }},
$$

where $\sum P_{\text {loss }}$ is the power loss of the DS. 
2.2. Increase the Balance among the Feeders (BF). Increasing the balance among the feeders in the DS helps to reduce the load of the heavy feeders and increase the load for the light feeders. It contributes to enhancing the available power capacity of the feeders as well as the distribution system. The suitable DG installation will improve the balance of the system. Thus, the second objective function considered is to enhance the balance among the feeders, which is determined by the following mathematical formulation:

$$
\min f_{2}=\operatorname{var}\left[S_{F, i}\right], \quad i=1, \ldots, N_{\mathrm{Fe}},
$$

where $S_{F, i}$ is the power energy of the $i$ th feeder, $N_{\mathrm{Fe}}$ is the number of feeders in the DS, and var is the variance function.

2.3. Increase the Balance among the Branches (BB). Enhancing the balance among the branches in the distribution system helps to transfer the loads from the heavy branches to other branches. It will help to increase the transferring capacity of the DS. The DG installation in the DS not only provides power for on-site demand but also contributes to reducing the overload and ensuring load balancing among branches. Therefore, the third objective function is to increase the balance among the branches, which is determined by the following mathematical formulation:

$$
\min f_{3}=\operatorname{var}\left[L C I_{i}\right], \quad i=1, \ldots, N_{\mathrm{br}}
$$

where $\mathrm{LCI}_{i}$ is the load carrying index of the $i$ th branch that is determined by the quotient of the load current flowing in the $i$ th branch and its rated current and $N_{\mathrm{br}}$ is the number of lines of the DS.

\subsection{Increase the Capacity of DGs Embedded in the DS (CDG).} Compared with the small capacity of DGs, the larger the capacity of DG is, the smaller the investment cost per unit of capacity is. However, the large DGs are usually installed in the transmission system. Thus, maximizing the DGs' capacity which can be pumped to the DS is one of the most effective solutions to entice investors paying for DG installation on the DS. Thus, the fourth goal function considered is to enhance the capacity of DGs connected to the distribution system, which is determined by the following mathematical formulation:

$$
\min f_{4}=\left(1-\frac{\sum_{i=1}^{N_{G}} P_{G, i}}{\sum P_{\mathrm{DG}, \max }}\right),
$$

where $P_{G, i}$ is the capacity of the $i$ th DG, $N_{G}$ is the number of DGs in the DS, and $\sum P_{\mathrm{DG} \text {, max }}$ is the total permitted capacity of DGs pumped to the distribution system.

2.5. Decrease the Deviation Voltage of the DS (DV). The DG placement is one of the most effective techniques to enhance the nodes' voltage of the DS and contribute to decreasing the voltage deviation. Thus, the deviation voltage reduction is the final objective function of the DG placement for multiobjective function. It is formulated as follows:

$$
\min f_{5}=V_{s}-V_{\text {min }},
$$

where $V_{s}$ is the amplitude of voltage at the slack bus and $V_{\text {min }}$ is the minimum amplitude of voltage in the distribution system.

2.6. Constraints of the DGs Placement on the DS. Integration of DG into the DS has not caused additional overload and over/underpermitted voltage. Thus, the following constraints must be ensured:

(i) Voltage and current limits:

$$
\begin{cases}V_{\min }^{\mathrm{li}} \leq V_{i} \leq V_{\max }^{\mathrm{li}}, & i=1,2, \ldots, N_{\mathrm{bu}}, \\ \mathrm{LCI}_{i} \leq \mathrm{LCI}_{\max }^{l i}, & i=1,2, \ldots, N_{\mathrm{br}} .\end{cases}
$$

(i) where $V_{\min }^{\mathrm{li}}$ and $V_{\max }^{\mathrm{li}}$ are the permitted lower and upper voltage limits. $\mathrm{LCI}_{i}$ is the load carrying index of the $i$ th branch. $\mathrm{LCI}_{\max }^{\mathrm{li}}$ is the permitted overload index. $N_{\text {bu }}$ is the number of nodes of the DS.

(ii) Capacity limits of DGs: the total capacity of the DGs has not been greater than the total loads and losses of distribution the system

$$
\sum_{i=1}^{N_{G}} P_{G, i} \leq \sum_{j=1}^{N_{\mathrm{bu}}} \operatorname{Load}_{j}+\sum P_{\text {loss }},
$$

(i) where $\operatorname{Load}_{j}$ is the $j$ th load of the DS.

\section{Improved Cuckoo Search Algorithm for the DG Placement on the DS}

In this section, the overview of ICSA is presented. In addition, the solution vector and the adaptive function for the DG placement with the multiobjective function are described. Finally, the application of ICSA for finding location and size of DGs is demonstrated. Details of the aforementioned sections are presented as follows.

3.1. Improved Cuckoo Search Algorithm. The ICSA is proposed based on the original CSA. Compared to CSA, ICSA is supplemented with a local search technique for exploiting around the so-far best solution. Thus, ICSA has the capability of finding results of the optimization problem with better quality than CSA. In [37], the effectiveness of ICSA has been also demonstrated to outperform many other improved versions of CSA. The details of ICSA for typical problem are depicted as follows:

Step 1 Initialization of the current population of solutions:

At the beginning of the ICSA, the current population of solutions is generated randomly as follows: 
$s_{i}=s_{\mathrm{lo}, j}+\rho_{1} \cdot\left(s_{\mathrm{hi}, j}-s_{\mathrm{lo}, j}\right), \quad i=1, \ldots, N_{s} ; j=1, \ldots, N_{v}$,

where $s_{i}$ is the $i$ th solution in the population with size of $N_{s} \cdot s_{\mathrm{lo}, j}$ and $s_{\mathrm{hi}, j}$ are the permitted lower and upper limits of the $j$ th variable. $N_{v}$ is the number of variables of the candidate solution vector. $\rho_{1}$ is a random number in $[0,1]$.

After the initial solutions are generated, their quality is validated by the adaptive function and the solution with the best adaptive function value $\left(Q_{\text {best }}\right)$ is considered as the so-far best solution $\left(s_{\text {best }}\right)$.

Step 2Production of new solutions based on the Lévy flight mechanism:

The Lévy flight mechanism helps to produce new solutions that distribute far from the current ones in the search space. It is formulated as follows:

$$
s_{\text {new }, i}=s_{i}+\vartheta \cdot\left(s_{i}-s_{\text {best }}\right) \otimes \operatorname{Lévy}(\theta),
$$

where $\vartheta$ is the step size that is often chosen to be $1 . \theta$ is distribution coefficient in $[0,2]$. Lévy $(\theta)$ is the Lévy distribution with the distribution coefficient $\theta . s_{\text {best }}$ is the so-far best solution. The symbol of $\otimes$ stands for the entry-wise multiplications.

After the new solutions are generated, their quality is validated. Then, the current population is updated based on the comparison between the adaptive function value of the new solutions and that of the corresponding ones in the old population. The updated population is performed by

$$
s_{i}= \begin{cases}s_{\text {new }, i}, & \text { if } Q_{\text {new }, i}<Q_{i}, \\ s_{i}, & \text { otherwise. }\end{cases}
$$

From the current population updated, the so-far best solution is updated again.

Step 3Production of new solutions based on the selective random walk mechanism:

The selective mechanism helps to produce new solutions that distribute near the current solutions. New solutions are created by adjusting a part of control variables of the current solutions. It is formulated as follows:

$$
s_{\text {new }, i}= \begin{cases}s_{i}+\rho_{2} \cdot\left(s_{k}-s_{h}\right), & \text { if } \rho_{3}<\mu, \\ s_{i}, & \text { otherwise, }\end{cases}
$$

where $\rho_{2}$ and $\rho_{3}$ are a random number in $[0,1] . \mu$ is the mutation index that is chosen to be $0.2 . s_{k}$ and $s_{h}$ are two candidate solutions taken randomly from the current population.

Then, equation (10) is used to renew the current population and the so-far best solution is updated one more time.
Step 4 Production of new solutions nearby the so-far best solution:

This mechanism helps to generate some new solutions in the vicinity of the so-far best solution by modifying a part of variables of the so-far best solution. However, this mechanism is not executed for each iteration, it is performed based on a comparison between the adaptive function value of the so-far best solution in two consecutive iterations. If the so-far best solution is not enhanced in two consecutive iterations, the mechanism is triggered as follows:

Firstly, there are $2 \cdot N_{v}$ new solutions generated by changing only one control variable of the so-far best solution as follows:

$$
\begin{aligned}
& s_{\text {new }, l}=M_{(k,:)} \cdot \tau_{1} \cdot \rho_{4}+s_{\text {best }}, \quad k=1, \ldots, N_{v} ; l=k, \\
& s_{\text {new }, l}=M_{(k,:)} \cdot \tau_{2} \cdot \rho_{5}+s_{\text {best }}, \quad k=1, \ldots, N_{v} ; l=l+k,
\end{aligned}
$$

where $M$ is the identity matrix of size $N_{v} \cdot \tau_{1}$ and $\tau_{2}$ are the space between the current variables and the new variables with $\tau_{1}>\tau_{2} \cdot \rho_{4}$ and $\rho_{5}$ are a random number between -1 and 1 .

Secondly, $2 \cdot N_{v}$ new solutions are also produced by adjusting some control variables of the so-far best solution as follows:

$$
s_{\text {new }, l}=\operatorname{Mr}_{(k,:)} \cdot \tau_{1} \cdot \rho_{6}+s_{\text {best }}, \quad k=1, \ldots, N_{v} ; l=l+k,
$$

$$
s_{\text {new }, l}=\operatorname{Mr}_{(k,:)} \cdot \tau_{2} \cdot \rho_{7}+s_{\text {best }}, \quad k=1, \ldots, N_{v} ; l=l+k \text {, }
$$

where $\rho_{6}$ and $\rho_{7}$ are random numbers between -1 and 1 .

In the above equations, $\mathrm{Mr}$ is a matrix of size $N_{v}$ by $N_{v}$ that its element is defined by the following equation:

$\operatorname{Mr}(t, h)=\left\{\begin{array}{ll}1, & \text { if } \rho_{7}>\sigma, \\ 0, & \text { otherwise, }\end{array} \quad t=1, \ldots, N_{v} ; h=1, \ldots, N_{v}\right.$,

where $\sigma$ is the scale factor that is usually set to $0.8 . \rho_{7}$ is a random number between 0 and 1 .

From $4 \cdot N_{v}$ new solutions generated, their quality is evaluated, and the so-far best solution is updated as follows:

$s_{\text {best }}=\left\{\begin{array}{ll}s_{\text {new }, l}, & \text { if } Q_{\text {new }, l}<Q_{\text {best }}, \\ s_{\text {best }}, & \text { otherwise. }\end{array} \quad l=1, \ldots, 4 \cdot N_{v}\right.$.

Steps 2 to 4 are implemented until the stopping condition is reached. 
3.2. Solution Vector. To apply ICSA for the DG placement problem, the unknown variables are location and size of DGs, in which, location of DG is one of the nodes of the DS except for the slack bus. Thus, the solution vector is expressed as follows:

$$
s_{i}=\left[\operatorname{Lo}_{j}^{i}, \mathrm{Si}_{j}^{i}\right], \quad i=1, \ldots, N_{s} ; j=1, \ldots, N_{G},
$$

where $\mathrm{Lo}_{j}^{i}$ represents location; meanwhile, $\mathrm{Si}_{j}^{i}$ represents size of the $j$ th DG in the $i$ th solution.

3.3. The Adaptive Function. To combine the five membership functions, the max-min approach is proposed for selecting the final solution as follows [38-43]:

$$
\mathrm{FS}=\max \left\{\min \left\{F_{j}\right\}\right\},
$$

where FS is the final quality of each candidate solution. $F_{j}$ is the normalized vector of the $j$ th objective function and expressed as follows:

$$
F_{j}= \begin{cases}1, & f_{j} \leq F_{j}^{\min }, \\ \frac{f_{j}^{\max }-f_{j}}{f_{j}^{\max }-f_{j}^{\min },} & f_{j}^{\min }<f_{j}<f_{j}^{\max }, \\ 0, & f_{j} \geq f_{j}^{\max },\end{cases}
$$

where $f_{j}^{\min }$ and $f_{j}^{\max }$ are, respectively, the minimum and maximums value of the $j$ th membership goal function. $f_{j}$ is the $j$ th objective function value.

From the fact that the value of each $F_{j}$ is not greater than one, the maximization problem described in (19) is altered to the minimization problem as follows [43]:

$$
\mathrm{FS}=1-\min \left\{F_{j}\right\} \text {. }
$$

In addition, each candidate solution has to satisfy the constraints of the DG placement problem consisting of current and voltage limits and capacity limit of DGs. Therefore, the adaptive function of the DG placement for multiobjective function is formulated as follows:

$$
\begin{aligned}
\min f= & K_{s} \cdot \mathrm{FS}+K_{p} \cdot\left[\left(\max \left(V_{\min }-V_{\min }^{\mathrm{li}}\right), 0\right)\right. \\
& \left.+\left(\max \left(V_{\max }-V_{\max }^{\mathrm{li}}\right), 0\right)+\left(\max \left(\mathrm{LCI}_{\max }-\mathrm{LCI}_{\max }^{\mathrm{li}}\right), 0\right)\right],
\end{aligned}
$$

where $K_{s}$ and $K_{p}$ are the scale factor and penalty coefficient, respectively. $V_{\max }$ and $V_{\min }$ are the maximum and minimum voltages and $\mathrm{LCI}_{\max }$ is the maximum load carrying index of the distribution system.

\subsection{Steps of ICSA for the DGs Placement on the Distribution} System. The location and the capacity of DGs are considered as control variables of the problem. These variables are selected by ICSA to satisfy the member goals and ensure the considered constraints, in which, the member goals consist of reducing power loss, improving the balance of feeders, improving the balance of branches, increasing the capacity of DGs, and decreasing voltage deviation meanwhile the constraints are limits of current, voltage, and DG capacity. For each candidate solution vector including the position and capacity of DGs, the bus data parameters of the distribution system are updated and the power flow problem is solved to calculate the value of the component target functions and the constraint conditions. Then, the solution vector's quality is determined by calculating the fitness function presented in (22). The process of creating and updating solution vector to find the best solution for the problem is done based on ICSA. The proposed ICSA application for the DG placement problem is described in detail as follows:

Step 1 Set control parameters of ICSA:

To apply ICSA for the DG placement, the control parameters of ICSA are required to be set before executing, consisting of population size $N_{s}$, dimension of the problem $N_{v}$, the space between the current variable and the new variable $\tau_{1}$ and $\tau_{2}$, and the maximum number of the adaptive function evaluations $\mathrm{AFE}_{\max }$. Step 2 Generate the current population of solutions: Generate randomly the current population by using (8) and adjust them according to (18) to be suitable for the DG placement problem.

Evaluate the quality of each candidate solution by the adaptive function as described in (22).

Determine the so-far best solution $s_{\text {best }}$ with the best adaptive function value $\left(Q_{\text {best }}\right)$.

Step 3 Generate new solutions based on the Lévy flight mechanism:

Generate the new solutions by (9) and adjust them according to (18).

Validate the quality of each new solution by using the adaptive function in (22).

Update the current population by using (10).

Update the so-far best solution $s_{\text {best }}$ with the best adaptive function value $\left(Q_{\text {best }}\right)$.

Step 4 Generate new solutions based on the selective random walk mechanism:

Generate the new solutions by using (11) and adjust them according to (18).

Evaluate the quality of each solution by using the adaptive function in (22).

Update the current population by using (10).

Update the so-far best solution $s_{\text {best }}$ with the best adaptive function value $\left(Q_{\text {best }}\right)$.

Step 5 Check the condition for triggering the mechanism of generating new solutions nearby the so-far best solution:

In this paper, the condition for activating the mechanism is based on the number of successive iterations that the so-far best adaptive function value is not improved $\left(\mathrm{it}_{\mathrm{lo}}\right)$. After $\mathrm{it}_{\mathrm{lo}}$ iterations, the so-far best 
solution is not enhanced; the mechanism of creating new solutions nearby the current best one is activated by performing step 6 . Otherwise, the searching process will move to step 7 .

Step 6 Generate new solutions nearby the so-far best solution:

In case of the mechanism activated, the following procedures are performed:

Generate $4 \cdot N_{v}$ new solutions by using (12) to (15) in turn and adjust them according to (18).

Validate the quality of each new solution by using the adaptive function in (22).

Update the so-far best solution $s_{\text {best }}$ with the best adaptive function value $\left(Q_{\text {best }}\right)$ by using (17).

Step 7 Check the stopping condition:

In general, ICSA will stop finding better solutions as the number of the adaptive function evaluations (AFE) reaches the maximum value $\mathrm{AFE}_{\max }$. However, in order to avoid wasting simulation time, an additional stopping condition is the maximum number of consecutive generations that the best solution function is not improved ( $\left.\mathrm{it}_{\mathrm{NIP}}\right)$. After it $\mathrm{it}_{\mathrm{NIP}}$ consecutive iterations, the sofar best solution is still not better than before, ICSA will stop searching, and the so-far best solution is examined as the optimal result of the DG placement problem with the multiobjective function. The steps of ICSA for the multiobjective DG placement are demonstrated in Figure 1 .

\section{Numerical Results}

In this section, the efficiency of the problem and the proposed method are evaluated on a practical distribution system [44]. It has the $11.4 \mathrm{kV}$ level, 11 feeders, and 13 open switches. The total active and reactive loads are $28.35 \mathrm{MW}$ and 20.70 MVAr, respectively. The diagram of the system is presented in Figure 2. The data of the system is referenced from [44]. In addition, the impact of uncertainty of DG on the obtained results is also analyzed in this section. The details of them are as follows:

4.1. Finding the Optimal Location and Size of DGs. For optimizing location and capacity of DGs in the system, the rated current of all branches is assumed equal to $200 \mathrm{~A}$. At the initial state, the power loss and the minimum voltage amplitude are $531.9924 \mathrm{~kW}$ and $0.9285 \mathrm{pu}$, respectively. The $\mathrm{BF}$ and BB indexes are 1.4418 and 0.1475 , respectively. Note that, with the rated current of $200 \mathrm{~A}$ for all branches, the maximum LCI of the system is 1.1748 . It means that there exists a branch that is overloaded about $17.48 \%$. The number of DGs connected to the system is limited to three.

For applying ICSA to find DGs' location and size, the population size $N_{s}$ is selected to be 30 . Because the number of DGs is limited to three, the dimension of the problem $N_{v}$ is set to 6 . The maximum number of the adaptive function evaluations $\mathrm{AFE}_{\max }$ is set to 18000 corresponding to about 300 iterations. The space between the current variable and

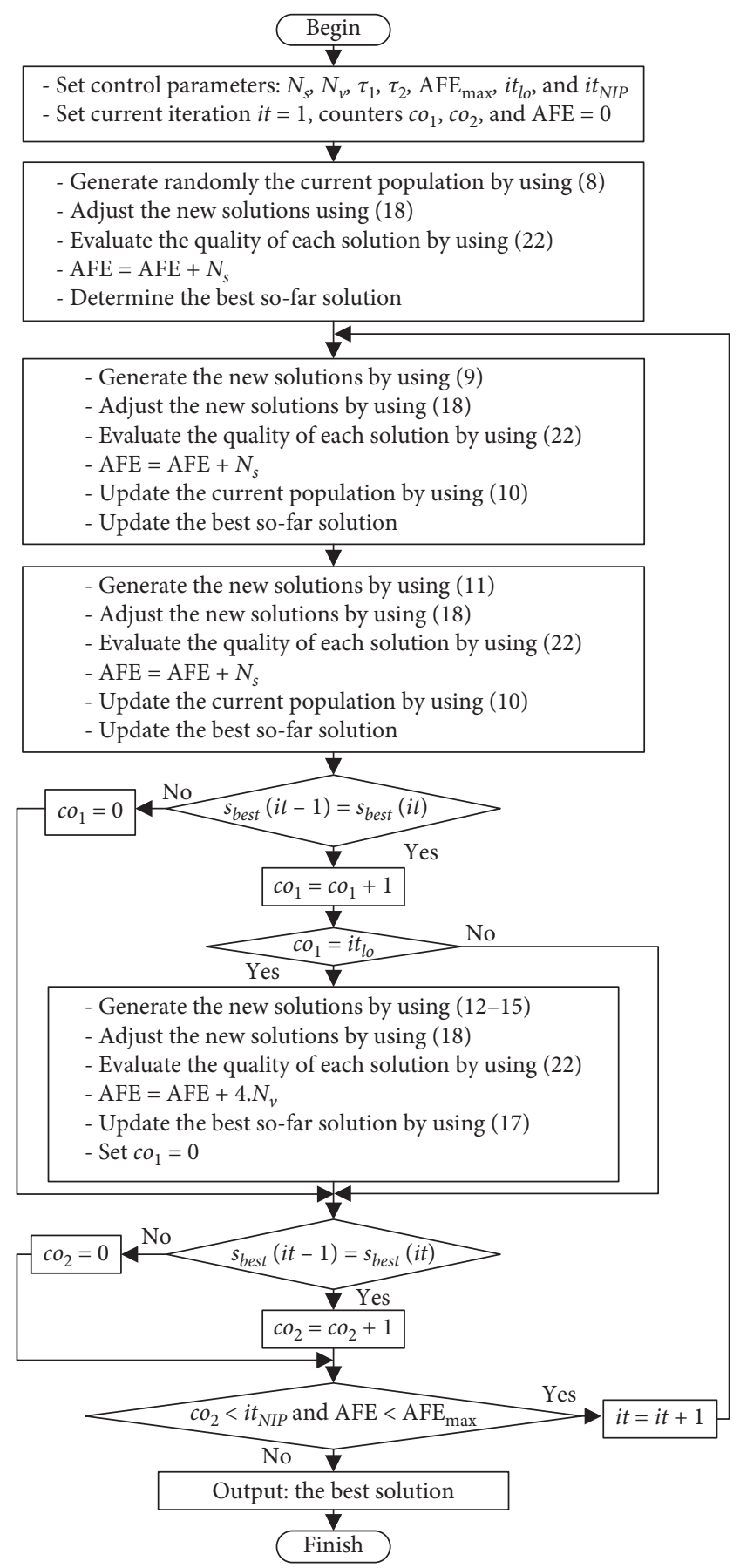

FIgURE 1: The flowchart of ICSA for the DGs placement problem.

the new variables $\tau_{1}$ and $\tau_{2}$ is, respectively, set to 4 and 2 . The number of consecutive iterations that the so-far best adaptive function value is not improved $\mathrm{it}_{\mathrm{lo}}$ is set to 3 . Finally, the maximum number of consecutive iterations that the best solution function is not improved it $\mathrm{NIP}_{\mathrm{NP}}$ is set to 50 . If the scale coefficient of the objective function is much smaller than the penalty coefficient for violation of constraints, the objective function value of the obtained solution will be trivial because the value of constraints takes a high portion in the adaptive function value which consists of the objective function and the constraints. Otherwise, if the scale 


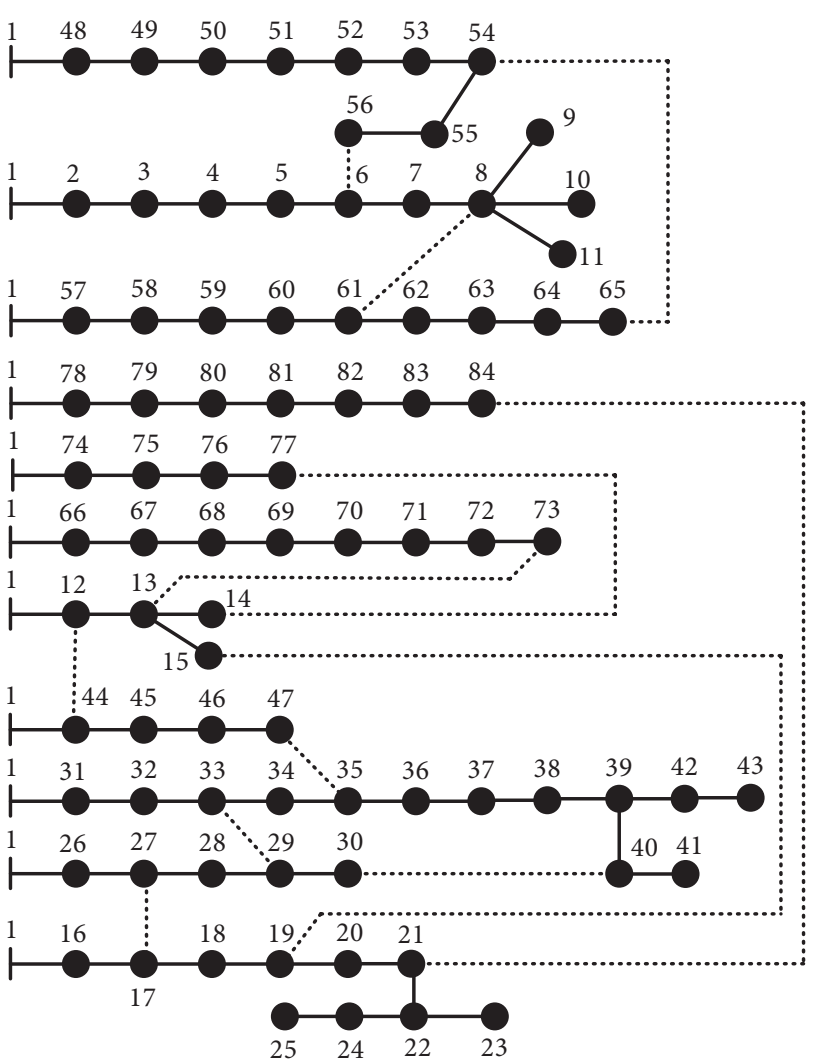

Figure 2: The 84-node test distribution system.

coefficient of the objective function is much higher than the penalty coefficient, the obtained solution may violate deeply the constraints. Based on the initial value of the objective functions and many experiments, the scale factor $K_{s}$ and penalty coefficient $K_{p}$ are selected to be 10000 and 1000 , respectively.

To calculate the adaptive function value for the multigoal function, the minimum and maximum values of the membership function described in (20) have to be determined. Thus, for obtaining the maximum and minimum values of each membership function, the ICSA is applied to solve the DG placement problem for each single-objective function to determine the minimum value of each membership function. The maximum value of each membership function is calculated based on the system without DG placement. Both of the maximum and minimum values for the membership functions are presented in Table 1.

The obtained results for the single-objective and multiobjective functions are shown in Table 2. By using the multigoal function, the optimal location and size of three DGs are $5.5357 \mathrm{MW}$ at the 80th node, $5.0542 \mathrm{MW}$ at the 6th node, and $5.4158 \mathrm{MW}$ at the 32 th node. For the total capacity of $16.0058 \mathrm{MW}$ located on the above locations, it caused the power loss of $416.7929 \mathrm{~kW}$, the BF of 0.8329 , the $\mathrm{BB}$ of 0.0949 , and the DV of 0.0512 corresponding to $V_{\min }$ of 0.9488 and $\mathrm{LCI}_{\max }$ of 1.1454 . It can be seen that all of these indexes have been improved compared to the case of without DG installation, in which, power loss has been decreased from $531.9924 \mathrm{~kW}$ to $416.7929 \mathrm{~kW}$. The BF and BB indexes
TABLE 1: The maximum and minimum values of the membership functions for the multigoal function.

\begin{tabular}{lccccc}
\hline Item & $f_{1}$ & $f_{2}$ & $f_{3}$ & $f_{4}$ & $f_{5}$ \\
\hline Maximum & 531.9924 & 1.4418 & 0.1475 & 1.0000 & 0.0715 \\
Minimum & 359.1712 & 0.3663 & 0.0949 & 0.0004 & 0.0399 \\
\hline
\end{tabular}

have been decreased from 1.4418 and 0.1475 to 0.8329 and 0.1177 , respectively. The minimum voltage has been raised from 0.9285 to 0.9488 and the maximum load carrying index has been reduced from 1.1748 to 1.1454 after installation of DGs. For the cases of single-objective optimization, the target index is significantly improved, but the other indicators, which are affected by location and capacity of DGs, are worse than those of the case of no DG installation. For example, for the single-objective function of power loss reduction, the total loss has been decreased from $531.9924 \mathrm{~kW}$ to $359.1712 \mathrm{~kW}$ corresponding to $32.49 \%$ reduction. The $\mathrm{BF}$ and $\mathrm{BB}$ indexes as well as the minimum voltage amplitude have also been improved after installing 9.2402 MW of DGs in the system. In more details, the BF and $\mathrm{BB}$ indexes have been reduced from 1.4418 and 0.1475 to 1.1321 and 0.1028 , respectively. The minimum voltage has been raised from $0.9285 \mathrm{pu}$ to $0.9556 \mathrm{pu}$. However, the $\mathrm{LCI}_{\max }$ index has not been improved after placing of DGs for power loss reduction. The target index is improved but the other indexes are worse than before for the case with the single-objective functions of BF, BB, CDG, and DV indexes. This situation has been completely overcome when solving the DG placement problem satisfying multiobjective function. The demonstration for this point can be viewed in Table 3. The balance among membership functions shown by their normalized vector value is better than that of the singleobjective functions with smaller standard deviation (STD) compared with other cases.

Figures 3 shows the current profiles of the system. From the figure, in the case of multigoal function, the load carrying index of branches reaches better balance than other cases. Except for the case of single-goal function of BB index, the maximum carrying factor index obtained by the multigoal function has been lower than that of other single-objective goals. The voltage profiles of all cases are shown in Figure 4. From the figure, the voltage profile has been enhanced significantly after installation of DGs by the multigoal function. In addition, except for the case of single-goal function of DV index, the voltage profile obtained in the case of multiobjective function is the best one with the better improvement compared to other cases. The capacity of feeders of all cases is presented in Figure 5. Similar to the current and voltage profiles, the capacity of feeders obtained in the case of multiobjective function can reach better balance than those of other cases except for the case of single-objective function of $\mathrm{BF}$ index.

The performance of ICSA for the multigoal DG placement as well as the single-objective functions is shown in Table 4. The convergence curve in each trial as well as the maximum, minimum, and average convergence curves in 30 trials for the multiobjective DG placement is presented in Figure 6. The convergence characters of ICSA for five single- 
TABle 2: Comparisons of the multiobjective function with five single-objective functions.

\begin{tabular}{|c|c|c|c|c|c|c|c|c|c|}
\hline $\begin{array}{l}\text { Objective function } \\
(\mathrm{OF})\end{array}$ & Location and size of DGs & PL $(\mathrm{kW})$ & $\mathrm{BF}$ & $\mathrm{BB}$ & CDG & DV & $\begin{array}{l}\sum \mathrm{DG} \\
(\mathrm{MW})\end{array}$ & $V_{\min }(\mathrm{pu})$ & $\mathrm{LCI}_{\max }$ \\
\hline No DGs & - & 531.9924 & 1.4418 & 0.1475 & 1 & 0.0715 & 0 & 0.9285 & 1.1748 \\
\hline $\operatorname{Min}\left(f_{1}\right)$ & $3.5835(80), 2.5263(72), 3.1304(7)$ & 359.1712 & 1.1321 & 0.1028 & 0.6741 & 0.0444 & 9.2402 & 0.9556 & 1.1748 \\
\hline $\operatorname{Min}\left(f_{2}\right)$ & $\begin{array}{c}5.2679(62), 4.8515(46), \\
5.2384(74)\end{array}$ & 673.5146 & 0.3663 & 0.1796 & 0.4583 & 0.0715 & 15.3577 & 0.9285 & 1.1748 \\
\hline $\operatorname{Min}\left(f_{3}\right)$ & $2.2288(41), 2.7389(9), 2.4391(25)$ & 439.7255 & 0.8396 & 0.0949 & 0.7387 & 0.0521 & 7.4069 & 0.9479 & 1.1688 \\
\hline $\operatorname{Min}\left(f_{4}\right)$ & $9.4350(32), 9.4303(2), 9.4731(78)$ & 654.703 & 3.741 & 0.1874 & 0.0004 & 0.0567 & 28.3384 & 0.9433 & 1.6567 \\
\hline $\operatorname{Min}\left(f_{5}\right)$ & $2.8674(83), 3.7468(8), 1.7221(72)$ & 378.0717 & 1.1011 & 0.1058 & 0.7060 & 0.0399 & 8.3362 & 0.9601 & 1.1748 \\
\hline Multiobj. & $5.5357(80), 5.0542(6), 5.4158(32)$ & 416.7929 & 0.8329 & 0.1177 & 0.4354 & 0.0512 & 16.0058 & 0.9488 & 1.1454 \\
\hline
\end{tabular}

TABLE 3: The balance among the membership functions.

\begin{tabular}{lcccccc}
\hline OF & $F_{1}$ & $F_{2}$ & $F_{3}$ & $F_{4}$ & $F_{5}$ & STD \\
\hline $\operatorname{Min}\left(f_{1}\right)$ & 1 & 0.2880 & 0.8498 & 0.3261 & 0.8576 & 0.3319 \\
$\operatorname{Min}\left(f_{2}\right)$ & 0 & 1 & 0 & 0.5419 & 0 & 0.4522 \\
$\operatorname{Min}\left(f_{3}\right)$ & 0.5339 & 0.5599 & 1 & 0.2614 & 0.6139 & 0.2649 \\
$\operatorname{Min}\left(f_{4}\right)$ & 0 & 0 & 0 & 1 & 0.4684 & 0.4434 \\
Min $\left(f_{5}\right)$ & 0.8906 & 0.3169 & 0.7928 & 0.2942 & 1 & 0.3309 \\
Multiobj. & 0.6666 & 0.5662 & 0.5665 & 0.5648 & 0.64241 & 0.0493 \\
\hline
\end{tabular}

objective functions are shown in Appendix, in which, the PL reduction is presented in Figure 7, the BF reduction is shown Figure 8, the $\mathrm{BB}$ reduction is presented in Figure 9; meanwhile, Figure 10 and Figure 11 show the objective of maximum of DGs capacity and deviation voltage reduction, respectively. From Table 4 and Figure 6, for the multiobjective function, ICSA usually converges about 115 iterations. The maximum number of convergence iterations is 201 iterations that has happened for only one trial though the maximum number of iterations is chosen to be 300 . This trend also occurs for the single-goal optimization cases. The short number of convergence iterations is due to the stopping condition of the algorithm. When the adaptive function between consecutive iterations is not improved, the number of iterations is not increased and recored as final iteration. Furthermore, the average curve for 30 runs converges very close to the minimum characteristic curve as well as the average adaptive function value is quite close to its minimum value with a small standard deviation. This demonstrates the stability of ICSA for optimizing location and size of DGs. The average run times of each trial for the multiobjective function are about 87.7417 seconds that is suitable for the complex practical system as the 84-node system. The achievement promises positive results for using ICSA to solve DG problem to satisfy other goals.

The multiobjective function in the paper is first proposed. Thus, in order to compare the effectiveness of ICSA with the previous studies, the single-goal optimization problem for power loss reduction is used. This single-goal optimization problem is also the case to find the smallest value of the power loss reduction membership function that ICSA has reached before solving the multiobjective problem. The results compared with some recent studies are demonstrated in Table 5. The results presented that the installation locations of the three DGs obtained are completely similar to those of the stochastic fractal search algorithm (SFSA) [45] and the exact loss formula-based analytical approach (ELF) [46] while the optimum power value of the DGs has a slight difference. Specifically, by using ICSA, the capacity of the DGs installed at the 80th, 72th, and 7th are 3.5835, 2.5263, and 3.304 MW, respectively, while this value is $\{3.5847(80), 2,883$ (72) 3,139 (7) $\}$ and $\{3.5996$ (80), 2.5166 (72), $3.1045(7)\}$ for SFSA and ELF. The power loss obtained by ICSA is $359.1712 \mathrm{~kW}$ while this value is 359.7300 and $359.2000 \mathrm{~kW}$ for SFSA and ELF, respectively, which are slightly higher than that of ICSA. The value of power loss obtained by using ICSA compared to the above methods shows the efficiency and reliability of the proposed ICSA approach.

4.2. Impact of Uncertainty of DG on the Obtained Results. In order to evaluate the impact of the DG uncertainty, the 2nd DG is assumed to be a wind turbine and the power of the remaining DGs is kept constant. In this case, based on the optimal DG size that has been gained by ICSA and the wind speed at the installation area, the DG capacity at different wind speed values and their effect on the technical indicators of the distribution system are evaluated as follows:

The uncertainty of wind speed can be modeled based on the Weibull PDF as follows [47-52]:

$$
f(v)=\frac{h}{c}\left(\frac{v}{c}\right)^{h-1} e^{-(v / c)^{2}},
$$

where $h$ is the shape coefficient that is chosen to be 2 [49]. $c$ is the scale coefficient that is chosen based on the mean wind speed at the installation area by $c=1.128 v_{\text {ave }}[49,53]$.

The probability of the state $i$ th with the wind speed in the range of $v_{i, 1}$ and $v_{i, 2}$ is determined as follows $[49,53]$ :

$$
\operatorname{Pro}\left(v_{i}\right)=\int_{v_{i, 1}}^{v_{i, 2}} f(v) \mathrm{d} v .
$$

The generated power of the DG based on wind turbine corresponding to the state $i$ th is calculated as follows [49]: 


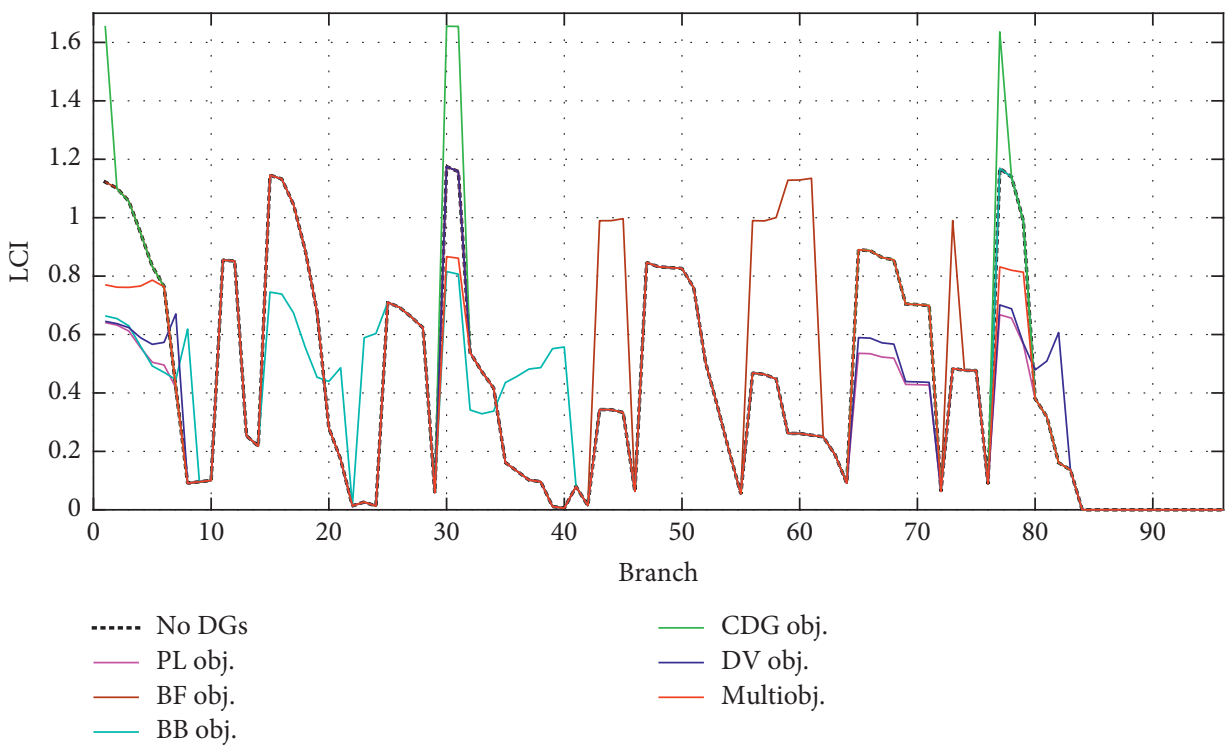

FIGURE 3: Load carrying index of branches of the 84-node system for the cases of DGs placements.

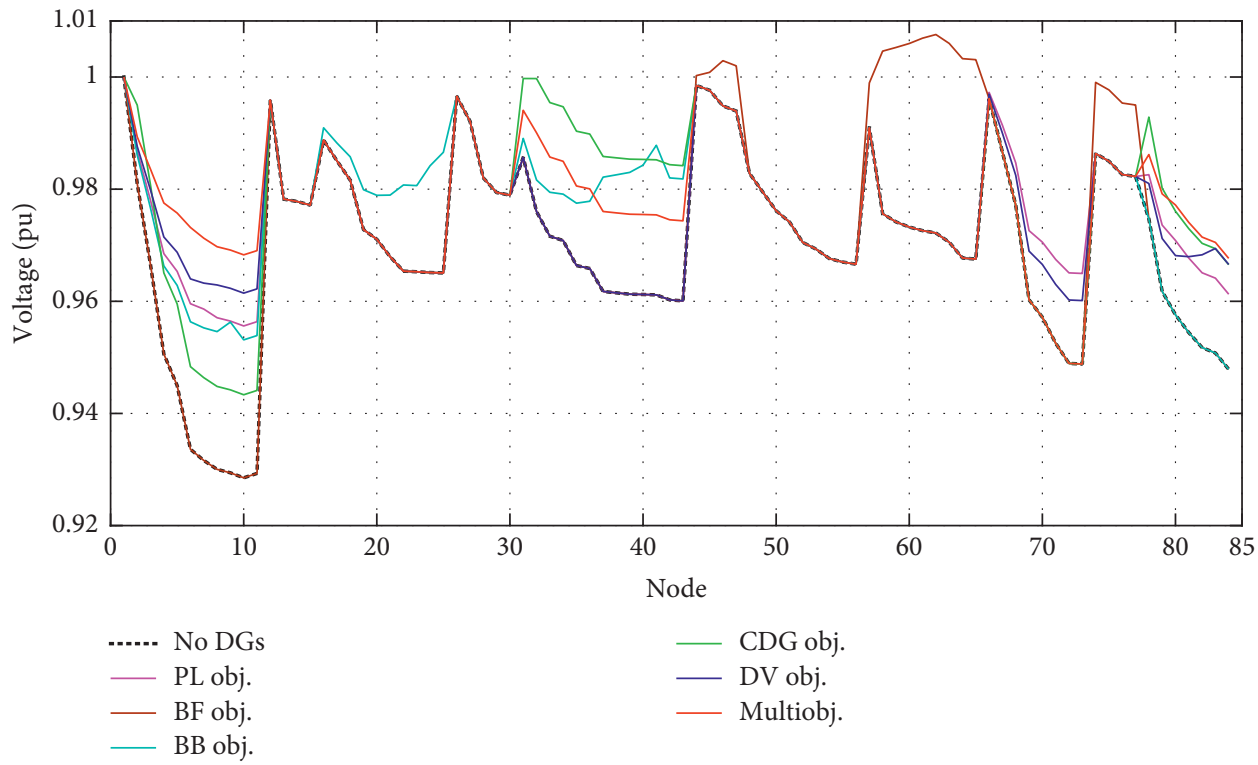

Figure 4: Voltages of the 84-node system for the cases of DGs placements.

$$
P_{i}= \begin{cases}0, & 0 \leq v_{\mathrm{mi}} \leq v_{\mathrm{ci}}, \\ P_{r} \frac{v_{\mathrm{mi}}-v_{\mathrm{ci}}}{v_{r}-v_{\mathrm{ci}}}, & v_{\mathrm{ci}} \leq v_{\mathrm{mi}} \leq v_{r}, \\ P_{r}, & v_{r} \leq v_{\mathrm{mi}} \leq v_{\mathrm{co}}, \\ 0, & v_{\mathrm{co}} \leq v_{\mathrm{mi}},\end{cases}
$$

where $v_{\mathrm{mi}}$ is the mean wind speed of the state $i$ th. $v_{\mathrm{ci}}$ and $v_{\mathrm{co}}$ are the cut-in and cut-off speeds of the DG and $v_{r}$ is its rated speed.

It is assumed that the wind speed at the DG installation area is divided into states including $0-4,4-8,8-12,12-16$,
$16-20$, and $20-25 \mathrm{~m} / \mathrm{s}$ and the mean wind speed at this area is $6.07 \mathrm{~m} / \mathrm{s}$. The parameters of the DG based on the wind turbine consisting of $v_{\mathrm{ci}}, v_{r}$, and $v_{\mathrm{co}}$ are, respectively, 4, 14, and $25 \mathrm{~m} / \mathrm{s}$. The probabilities of the speed states based on the Weibull PDF model according to (23) and (24) are given in Figure 12.

The obtained parameters of the wind speed state and the output power of DG corresponding to the velocity states are given in Table 6 , wherein the 1 st column indicates the name of the wind speed states. The 2 nd and $3 \mathrm{rd}$ columns indicate the speed limits and the mean speed of the states. The 4 th column shows the probability values of each state that are determined by (24). The 5th column presents the output power of the DG for each state, which is obtained by (25). 


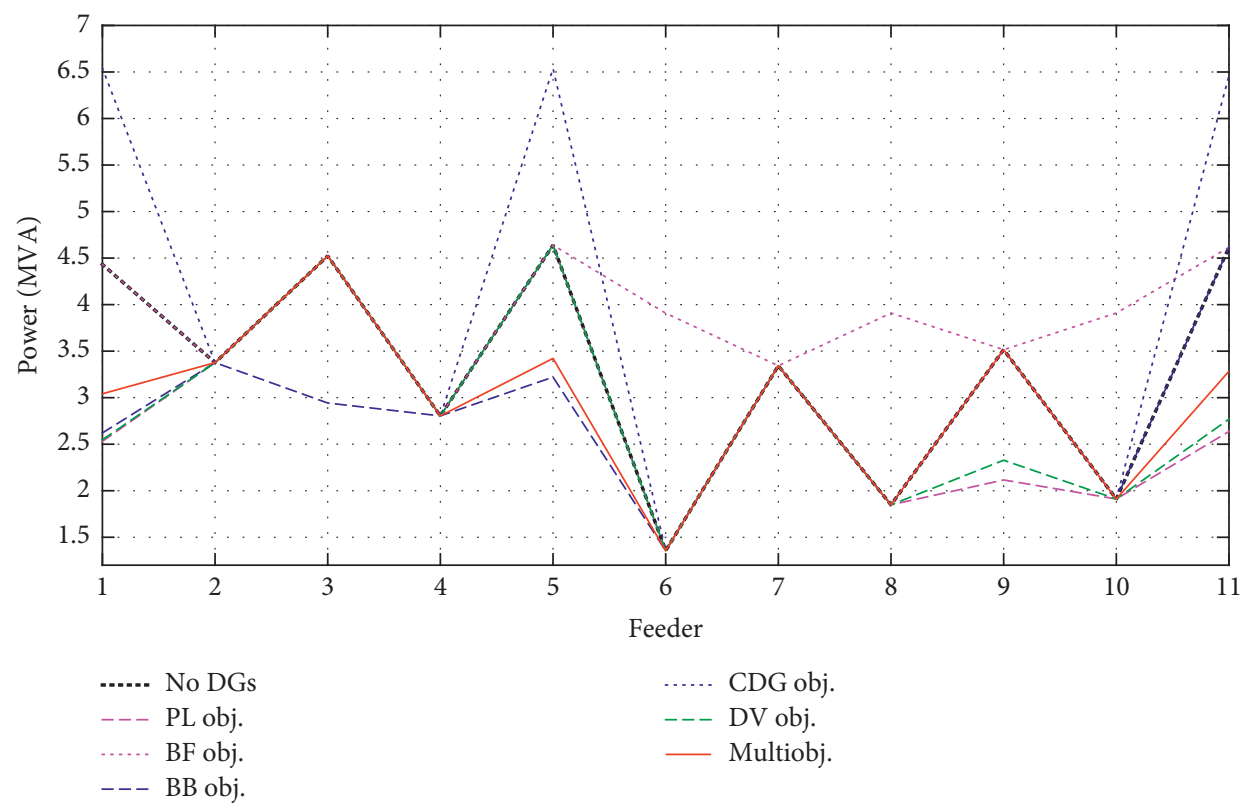

FIgURE 5: The capacity of feeders of the 84-node system for the cases of DGs placements.

TABLE 4: The performance of ICSA for the DGs placement in the 84-node system.

\begin{tabular}{|c|c|c|c|c|c|c|c|c|}
\hline \multirow{2}{*}{ OF } & \multicolumn{4}{|c|}{ The adaptive function } & \multicolumn{3}{|c|}{ Convergence iteration } & \multirow{2}{*}{ Run times (sec) } \\
\hline & Max. & Min. & Average & Standard deviation & Max. & Average & Standard deviation & \\
\hline $\operatorname{Min}\left(f_{1}\right)$ & 3713189 & 3591887 & 3632150 & 32755 & 123 & 86 & 15.8739 & 59.676 \\
\hline $\operatorname{Min}\left(f_{2}\right)$ & 6656.3658 & 3859.2445 & 4849.6476 & 1232 & 202 & 107 & 39.5122 & 80.9646 \\
\hline $\operatorname{Min}\left(f_{3}\right)$ & 1144.2555 & 1119.5946 & 1138.7884 & 5.5796 & 108 & 69 & 11.0451 & 49.4073 \\
\hline $\operatorname{Min}\left(f_{4}\right)$ & 832.5342 & 667.4547 & 735.4465 & 39.6525 & 211 & 96 & 37.4920 & 92.1776 \\
\hline $\operatorname{Min}\left(f_{5}\right)$ & 574.0958 & 574.0958 & 574.0958 & 0 & 95 & 19 & 9.3371 & 46.8115 \\
\hline Multiobj. & 5489.4966 & 4498.5513 & 4700.1722 & 205.6555 & 201 & 115 & 41.8766 & 87.7417 \\
\hline
\end{tabular}

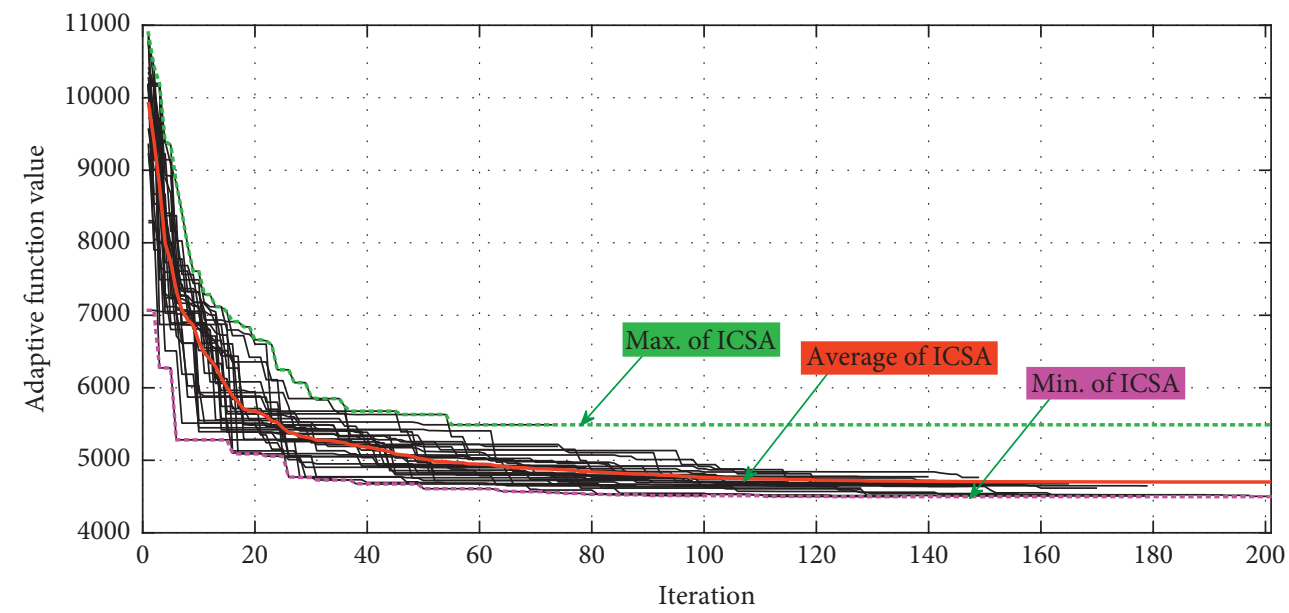

Figure 6: Convergence curves for the multiobjective function. 


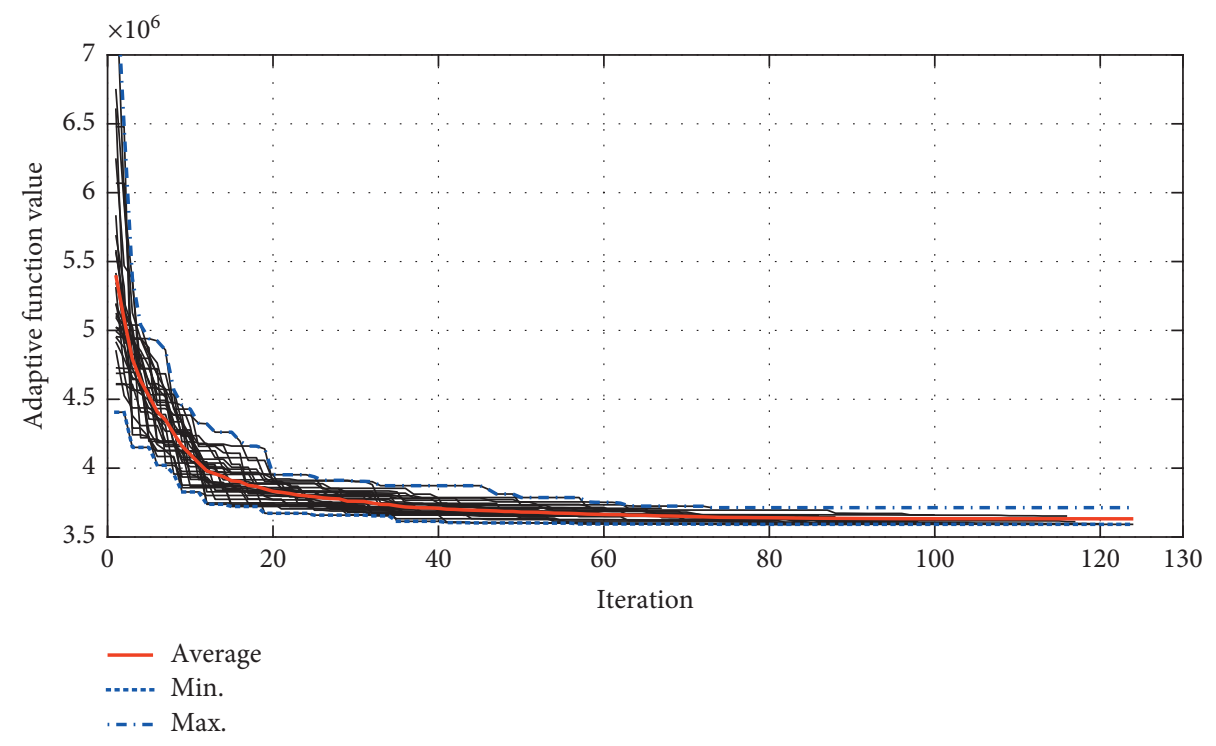

Figure 7: Convergence curves for the single-goal function of PL reduction.

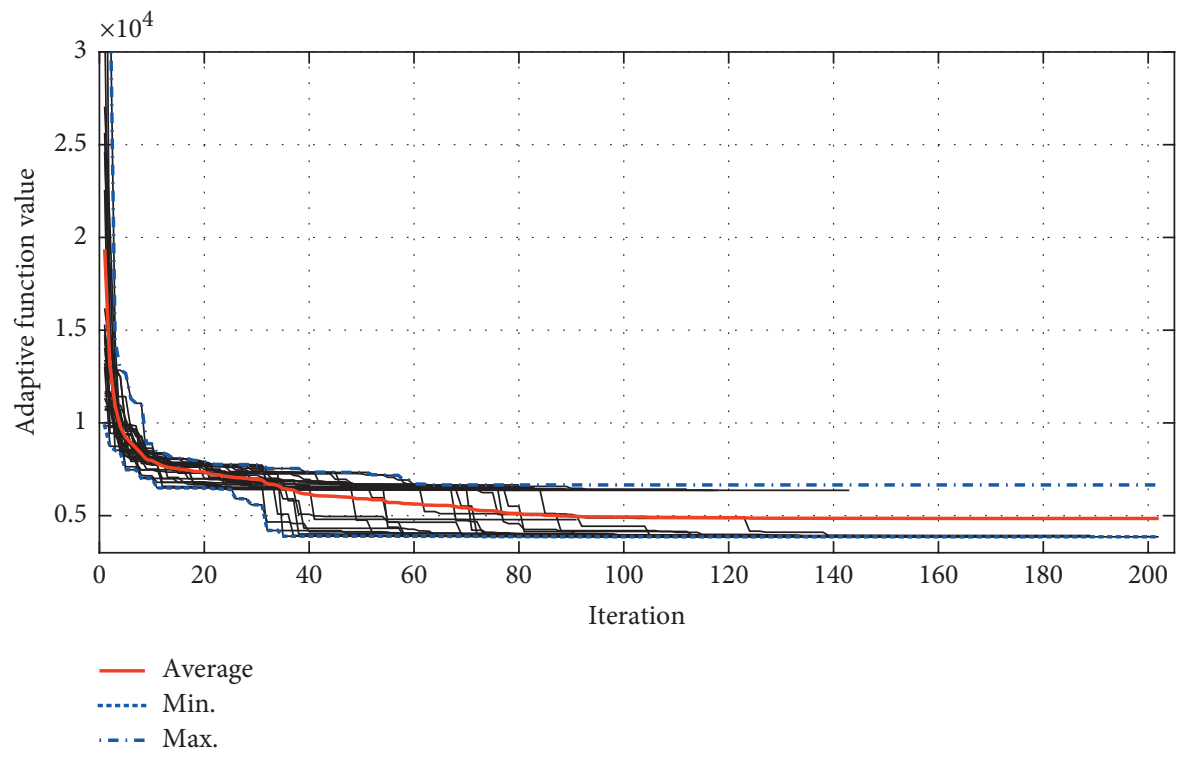

FIgURE 8: Convergence curves for the single-goal function of BF reduction.

The results show that, when the wind speed is lower than the rated speed of the DG, the generated power of the DG decreases. Specifically, when the wind speed is below the cutoff value, the output power of DG is 0 and when the wind speed is in the range of $4-8 \mathrm{~m} / \mathrm{s}$ in the state no. 2 , the DG's power only reaches $1.01084 \mathrm{MW}$ corresponding to about $20 \%$ of its rated power or in the state no. 3 , the DG's power reaches $3.03252 \mathrm{MW}$ corresponding to about $60 \%$ of the rated power when the wind speed reaches $8-12 \mathrm{~m} / \mathrm{s}$. Thus, it is necessary to validate the impact of the output power of this DG at the states no. 1, no. 2, and no. 3 on the technical factors of the distribution system. It is noted that the states no. 4 , no. 5 , and no. 6 are identical to the optimal solution in the case of multigoal function DG placement and the state no. 7 is similar to the state no. 1 .

The calculation results for the states no. 1 to no. 4 are given in Table 7. For the states no. 1 and no. 2, the component target functions including $\mathrm{PL}, \mathrm{BF}, \mathrm{BB}, \mathrm{CDG}$, and DV are all higher than those of the state no. 4 wherein their value reaches the worst value for the state no. 1 . For the state no. 3 when DG output power reaches $60 \%$ of the rated capacity, the power loss and load balancing index among the branches are lower than that of the state no. 4 , but the feeder balance index and the DG capacity index are higher than those of the state no. 4 . Therefore, it can be seen that the technical indicators 


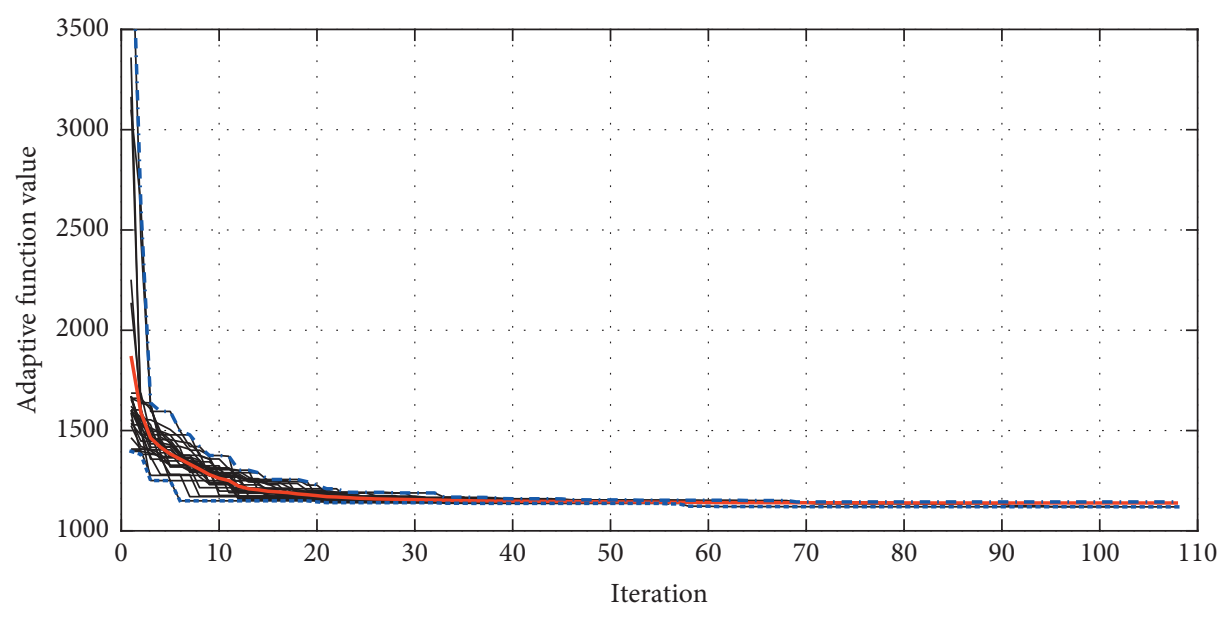

_.... Min.
.$\ldots$... Max.

FIgURE 9: Convergence curves for the single-goal function of BB reduction.

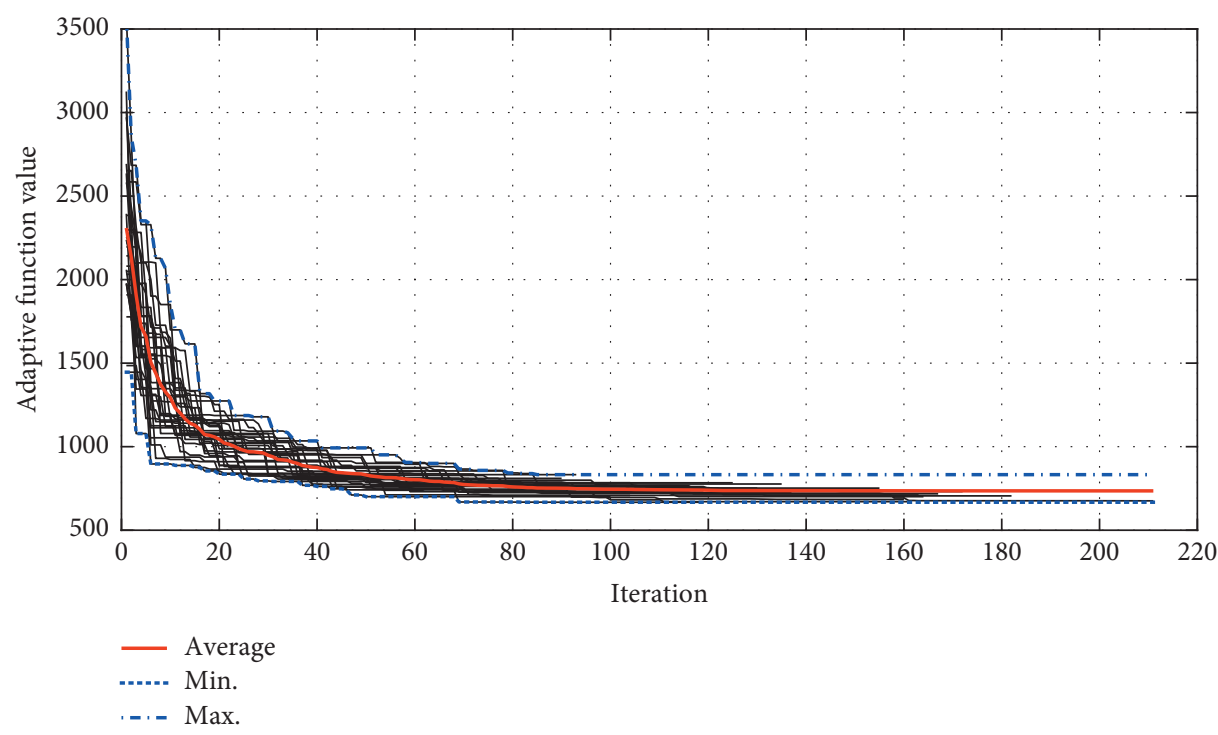

FIGURE 10: Convergence curves for the single-goal function of maximum of DGs capacity.

have been negatively affected when the wind speed changes.

The balance among the member target functions given in Figure 13 shows that state no. 3 is the best one compared to the states no. 1 and no. 2 when the balance characteristic among member functions is almost similar to the state no. 4. The comparison of capacity among feeders, load carrying coefficient among branches, and node voltage for the wind speed states are shown in Figures $8(\mathrm{~b})-8(\mathrm{~d})$, respectively. When the DG output power is much lower than its rated value, it can cause high voltage drop and power loss in the system. Therefore, the process of designing, installing, and operating DG based on renewable energy such as wind turbine should consider the uncertainty of DG to determine suitable operation measures. 


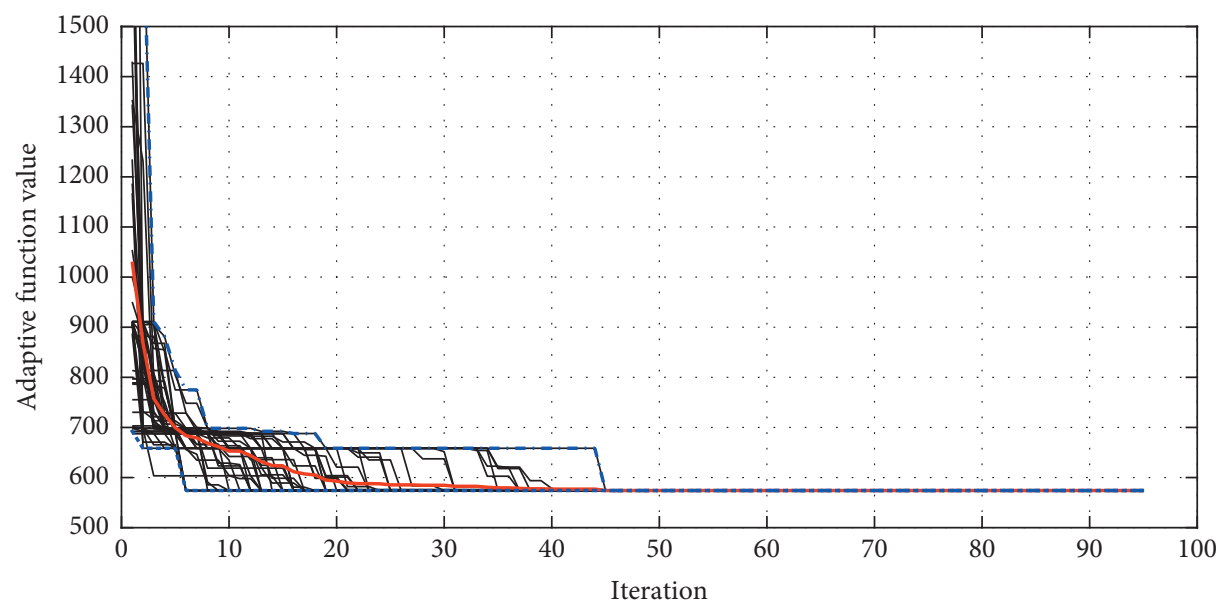

$$
\begin{aligned}
& \text { _.... Min. } \\
& \text {... Mverage } \\
& \text {... Max. }
\end{aligned}
$$

\begin{tabular}{|c|c|c|c|c|c|c|c|c|}
\hline Method & Location and size of DGs & $\Delta \mathrm{p}(\mathrm{kW})$ & Loss reduction & $\mathrm{BF}$ & BB & $\sum \mathrm{DG}(\mathrm{MW})$ & $V_{\min }(\mathrm{pu})$ & $\mathrm{LCI}_{\max }$ \\
\hline No & - & 531.9924 & - & 1.4418 & 0.1475 & 0 & 0.9285 & 1.1748 \\
\hline ICSA & $3.5835(80), 2.5263$ & 12 & $32.49 \%$ & 1.1321 & 0.1028 & 9.2402 & 0. & 1.1748 \\
\hline SFSA [45] & $3.5847(80), 2.8350(72) 3.1389(7)$ & 359.7300 & $32.38 \%$ & - & - & 9.5586 & 0.9557 & - \\
\hline ELF [46] & $3.5996(80), 2.5166(72), 3.1045(7)$ & 359.2000 & $32.48 \%$ & - & - & 9.2207 & 0.9554 & - \\
\hline
\end{tabular}

FIgURE 11: Convergence curves for the single-goal function of deviation voltage reduction.

TABLE 5: Comparisons of the single-goal function of power loss reduction with other methods.

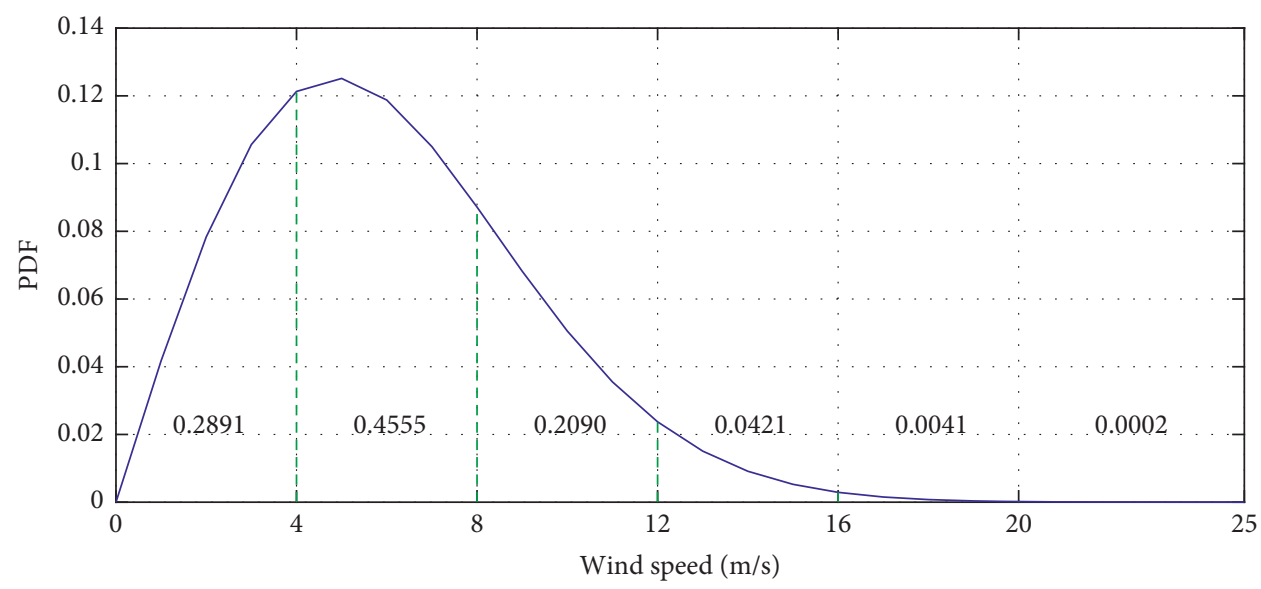

FIGURE 12: Weibull PDF corresponding to wind speed states.

TABLE 6: Wind speed probabilities and the corresponding power of the DG.

\begin{tabular}{lcccc}
\hline State & $v_{i}$ & $v_{m i}$ & Pro $\left(v_{i}\right)$ & $P_{i}(\mathrm{MW})$ \\
\hline State no. 1 & $0-4$ & 4 & 0.2891 & 0 \\
State no. 2 & $4-8$ & 6 & 0.4555 & 1.01084 \\
State no. 3 & $8-12$ & 10 & 0.2090 & 3.03252 \\
State no. 4 & $12-16$ & 14 & 0.0421 & 5.0542 \\
State no. 5 & $16-20$ & 18 & 0.0041 & 5.0542 \\
State no. 6 & $20-25$ & 22.5 & 0.0002 & 5.0542 \\
State no. 7 & $>25$ & - & 0 & 0 \\
\hline
\end{tabular}


TABLE 7: Impacts of the DG output power on technical indicators of the distribution system.

\begin{tabular}{|c|c|c|c|c|c|c|c|c|c|}
\hline State & Location and size of DGs & $\mathrm{PL}(\mathrm{kW})$ & $\mathrm{BF}$ & BB & CDG & DV & $\sum \mathrm{DG}(\mathrm{MW})$ & $V_{\min }(\mathrm{pu})$ & $\mathrm{LCI}_{\max }$ \\
\hline & & & & 0.1305 & 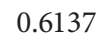 & 00715 & & & \\
\hline & 32) & & & & & & & & 454 \\
\hline State & $5.5357(8$ & & 0.8458 & & & 0.0 & & & 1.1454 \\
\hline State no. 4 (multiobj.) & $5.5357(80), 5.0542(6), 5.4158(32)$ & 416.7929 & 0.8329 & 0.1177 & 0.4354 & 0.0512 & 16.0058 & 0.9488 & 1.1454 \\
\hline
\end{tabular}

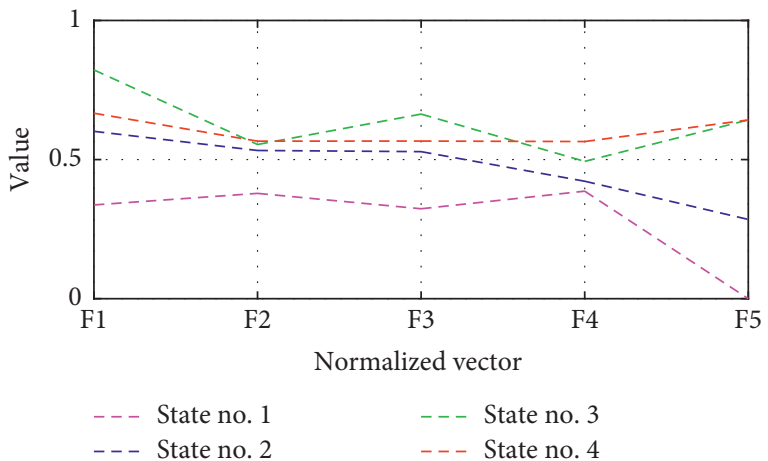

(a)

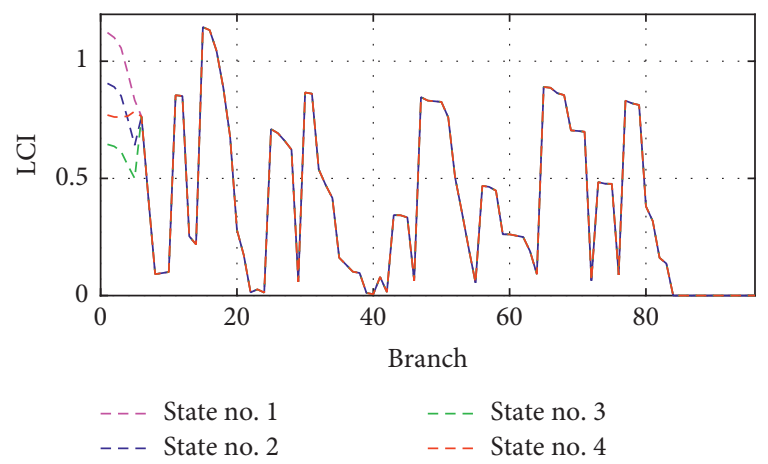

(c)

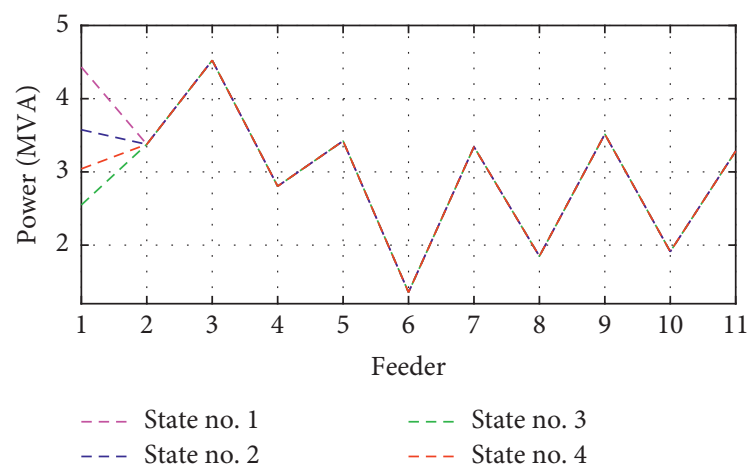

(b)

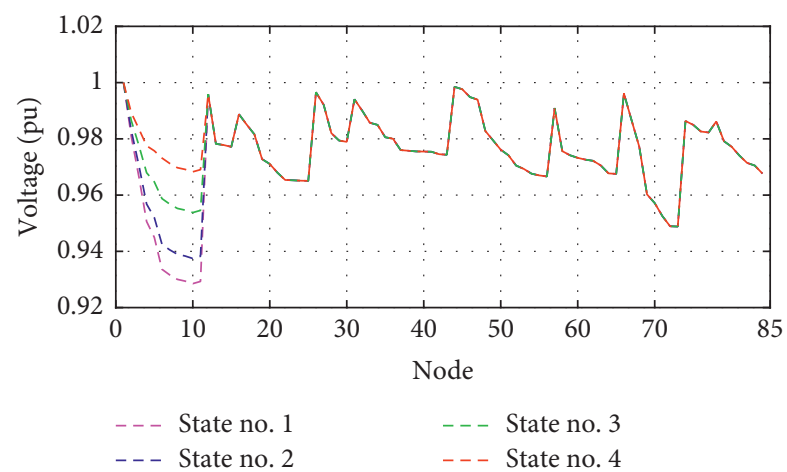

(d)

FIGURE 13: The balance among member functions, feeder and branch balance, and the node voltages corresponding to wind speed states.

\section{Conclusion}

Placement of DGs in the DS not only reduces power loss but also affects many other technical factors of the DS. This paper presents the method of optimizing the location and capacity of DGs in the DS to satisfy the technical criteria including power loss reduction, increase of balance among feeders as well as balance among branches, and voltage deviation reduction. In addition, to attract investment for installing of DGs on the DS, the maximizing DG's capacity that can be pumped to the DS is also considered as a membership objective function. In terms of the solving method, ICSA is first proposed to apply for the problem of optimizing position and size of DGs. The simulated results on the practical complex distribution system show that the indicators that need to be optimized are improved by using the multiobjective problem and the satisfaction among component objectives is better than the results gained by using the single-objective problems. In addition, the uncertainty of DG is also evaluated to show the negative impacts of the uncertainty of DG on the indicators of the system. Furthermore, the comparisons of ICSA with other studies in the literature have also shown that the effectiveness of ICSA is remarkable and promising to be one of the most reliable methods for DG installation problem.

\section{Data Availability}

Data of the 84-node distribution system were taken from [44].

\section{Conflicts of Interest}

The authors declare that they have no conflicts of interest regarding the publication of this paper. 


\section{References}

[1] K. Alanne and A. Saari, "Distributed energy generation and sustainable development," Renewable and Sustainable Energy Reviews, vol. 10, no. 6, pp. 539-558, 2006.

[2] T. Ackermann, G. Andersson, and L. Söder, "Distributed generation: a definition," Electric Power Systems Research, vol. 57, no. 3, pp. 195-204, 2001.

[3] N. Acharya, P. Mahat, and N. Mithulananthan, "An analytical approach for DG allocation in primary distribution network," International Journal of Electrical Power \& Energy Systems, vol. 28, no. 10, pp. 669-678, 2006.

[4] P. Paliwal, N. P. Patidar, and R. K. Nema, "Planning of grid integrated distributed generators: a review of technology, objectives and techniques," Renewable and Sustainable Energy Reviews, vol. 40, pp. 557-570, 2014.

[5] W. L. Theo, J. S. Lim, W. S. Ho, H. Hashim, and C. T. Lee, "Review of distributed generation (DG) system planning and optimisation techniques: comparison of numerical and mathematical modelling methods," Renewable and Sustainable Energy Reviews, vol. 67, pp. 531-573, 2017.

[6] S. Ganguly and D. Samajpati, "Distributed generation allocation on radial distribution networks under uncertainties of load and generation using genetic algorithm," Institute of Electrical and Electronics Engineers Transactions on Sustainable Energy, vol. 6, no. 3, pp. 688-697, 2015.

[7] N. Phuangpornpitak and S. Tia, "Optimal photovoltaic placement by self-organizing hierarchical binary particle swarm optimization in distribution systems," Energy Procedia, vol. 89, pp. 69-77, 2016.

[8] S. A. ChithraDevi, L. Lakshminarasimman, and R. Balamurugan, "Stud Krill herd Algorithm for multiple DG placement and sizing in a radial distribution system," Engineering Science and Technology, an International Journal, vol. 20, no. 2, pp. 748-759, 2017.

[9] T. N. Ton, T. T. Nguyen, A. V. Truong, and T. P. Vu, "Optimal location and size of distributed generators in an electric distribution system based on a novel metaheuristic algorithm," Engineering, Technology \& Applied Science Research, vol. 10, no. 1, pp. 5325-5329, 2020.

[10] N. Khuan, S. R. A. Rahim, M. H. Hussain, A. Azmi, and S. A. Azmi, "Integration of distributed generation and compensating capacitor in radial distribution system via firefly algorithm," Indonesian Journal of Electrical Engineering and Computer Science, vol. 16, no. 1, pp. 67-73, 2019.

[11] M. Abdelbadea, T. A. Boghdady, and D. Khalil Ibrahim, "Enhancing active radial distribution networks by optimal sizing and placement of DGs using modified crow search algorithm," Indonesian Journal of Electrical Engineering and Computer Science, vol. 16, no. 3, pp. 1179-1188, 2019.

[12] A. Rajendran and K. Narayanan, "Optimal multiple installation of DG and capacitor for energy loss reduction and loadability enhancement in the radial distribution network using the hybrid WIPSO-GSA algorithm," International Journal of Ambient Energy, vol. 41, no. 2, pp. 129-141, 2018.

[13] T. P. Nguyen, D. N. Vo, and T. T. Tran, "Optimal number, location, and size of distributed generators in distribution systems by symbiotic organism search based method," Advances in Electrical and Electronic Engineering, vol. 15, no. 5, pp. 724-735, 2018.

[14] M. Subramaniyan, S. Subramaniyan, M. Veeraswamy, and V. R. Jawalkar, "Optimal reconfiguration/distributed generation integration in distribution system using adaptive weighted improved discrete particle swarm optimization,"
COMPEL-The international journal for computation and mathematics in electrical and electronic engineering, vol. 38, no. 1, pp. 247-262, Article ID 08-2017-0344, 2018.

[15] D. Q. Hung and N. Mithulananthan, "Multiple distributed generator placement in primary distribution networks for loss reduction," Institute of Electrical and Electronics Engineers Transactions on Industrial Electronics, vol. 60, no. 4, pp. 1700-1708, 2013.

[16] D. Rama Prabha and T. Jayabarathi, "Optimal placement and sizing of multiple distributed generating units in distribution networks by invasive weed optimization algorithm," Ain Shams Engineering Journal, vol. 7, no. 2, pp. 683-694, 2016.

[17] A. El-Fergany, "Optimal allocation of multi-type distributed generators using backtracking search optimization algorithm," International Journal of Electrical Power \& Energy Systems, vol. 64, pp. 1197-1205, 2015.

[18] S. Sultana and P. K. Roy, "Multi-objective quasi-oppositional teaching learning based optimization for optimal location of distributed generator in radial distribution systems," International Journal of Electrical Power \& Energy Systems, vol. 63, pp. 534-545, 2014.

[19] M. Nayeripour, E. Mahboubi-Moghaddam, J. Aghaei, and A. Azizi-Vahed, "Multi-objective placement and sizing of DGs in distribution networks ensuring transient stability using hybrid evolutionary algorithm," Renewable and Sustainable Energy Reviews, vol. 25, pp. 759-767, 2013.

[20] M. H. Moradi, A. Zeinalzadeh, Y. Mohammadi, and M. Abedini, "An efficient hybrid method for solving the optimal sitting and sizing problem of DG and shunt capacitor banks simultaneously based on imperialist competitive algorithm and genetic algorithm," International Journal of Electrical Power \& Energy Systems, vol. 54, pp. 101-111, 2014.

[21] A. Keane and M. O'Malley, "Optimal allocation of embedded generation on distribution networks," Institute of Electrical and Electronics Engineers Transactions on Power Systems, vol. 20, no. 3, pp. 1640-1646, 2005.

[22] S. Kaur, G. Kumbhar, and J. Sharma, "A MINLP technique for optimal placement of multiple DG units in distribution systems," International Journal of Electrical Power \& Energy Systems, vol. 63, pp. 609-617, 2014.

[23] Y. M. Atwa, E. F. El-Saadany, M. M. A. Salama, and R. Seethapathy, "Optimal renewable resources mix for distribution system energy loss minimization," Institute of Electrical and Electronics Engineers Transactions on Power Systems, vol. 25, no. 1, pp. 360-370, 2010.

[24] N. Khalesi, N. Rezaei, and M. -R. Haghifam, "DG allocation with application of dynamic programming for loss reduction and reliability improvement," International Journal of Electrical Power \& Energy Systems, vol. 33, no. 2, pp. 288-295, 2011.

[25] N. Ghadimi, "Using HBMO algorithm to optimal sizing \& sitting of distributed generation in power system," Bulletin of Electrical Engineering and Informatics, vol. 3, no. 1, pp. 1-8, 2014.

[26] T. T. Nguyen, A. V. Truong, and T. A. Phung, "A novel method based on adaptive cuckoo search for optimal network reconfiguration and distributed generation allocation in distribution network," International Journal of Electrical Power \& Energy Systems, vol. 78, pp. 801-815, 2016.

[27] A. V. Truong, T. N. Ton, T. T. Nguyen, and T. L. Duong, “Two states for optimal position and capacity of distributed generators considering network reconfiguration for power loss minimization based on runner root algorithm," Energies, vol. 12, no. 1, p. 106, 2019. 
[28] K. S. Sambaiah and T. Jayabarathi, "Optimal reconfiguration and renewable distributed generation allocation in electric distribution systems," International Journal of Ambient Energy, vol. 0, no. 0, pp. 1-14, 2019.

[29] X. S. Yang and S. Deb, "Cuckoo Search via Lévy Flights," in Proceedings of the 2009 World Congress on Nature And Biologically Inspired Computing, NABIC 2009-Proceedings, pp. 210-214, Coimbatore, India, December 2009.

[30] X.-S. Yang and S. Deb, "Cuckoo search: recent advances and applications," Neural Computing and Applications, vol. 24, no. 1, pp. 169-174, 2014.

[31] T. T. Nguyen, D. N. Vo, and A. V. Truong, "Cuckoo search algorithm for short-term hydrothermal scheduling," Applied Energy, vol. 132, pp. 276-287, 2014.

[32] Z. Moravej and A. Akhlaghi, "A novel approach based on cuckoo search for DG allocation in distribution network," International Journal of Electrical Power \& Energy Systems, vol. 44, no. 1, pp. 672-679, 2013.

[33] T. T. Nguyen and A. V. Truong, "Distribution network reconfiguration for power loss minimization and voltage profile improvement using cuckoo search algorithm," International Journal of Electrical Power \& Energy Systems, vol. 68, pp. 233-242, 2015.

[34] E. Afzalan and M. Joorabian, "An improved cuckoo search algorithm for power economic load dispatch," International Transactions On Electrical Energy Systems, vol. 25, no. 6, pp. $958-975,2015$.

[35] A. Majumder and D. Laha, "A new cuckoo search algorithm for 2-machine robotic cell scheduling problem with sequencedependent setup times," Swarm and Evolutionary Computation, vol. 28, pp. 131-143, 2016.

[36] H. Rakhshani and A. Rahati, "Snap-drift cuckoo search: a novel cuckoo search optimization algorithm," Applied Soft Computing, vol. 52, pp. 771-794, 2017.

[37] T. T. Nguyen and T. T. Nguyen, "An improved cuckoo search algorithm for the problem of electric distribution network reconfiguration," Applied Soft Computing, vol. 84, p. 105720, 2019.

[38] G. A. A. Brigatto, C. C. B. Carmargo, and E. T. Sica, "Multiobjective Optimization of Distributed Generation Portfolio Insertion Strategies," in Proceedings of the 2010 IEEE/PES Transmission And Distribution Conference And Exposition, pp. 622-628, Latin America, T and D-LA, New Orleans, LA, USA, November 2010.

[39] I. J. Ramírez-Rosado and J. A. Domínguez-Navarro, "Possibilistic model based on fuzzy sets for the multiobjective optimal planning of electric power distribution networks," Institute of Electrical and Electronics Engineers Transactions on Power Systems, vol. 19, no. 4, pp. 1801-1810, 2004.

[40] M. -R. Haghifam, H. Falaghi, and O. P. Malik, "Risk-based distributed generation placement," IET Generation, Transmission \& Distribution, vol. 2, no. 2, pp. 252-260, 2008.

[41] K. Nekooei, M. M. Farsangi, H. Nezamabadi-pour, and K. Y. Lee, "An improved multi-objective harmony search for optimal placement of DGs in distribution systems," Institute of Electrical and Electronics Transactions on Smart Grid, vol. 4, no. 1, pp. 557-567, 2013.

[42] D. Sudha Rani, N. Subrahmanyam, and M. Sydulu, "MultiObjective Invasive Weed Optimization - an application to optimal network reconfiguration in radial distribution systems," International Journal of Electrical Power \& Energy Systems, vol. 73, pp. 932-942, 2015.

[43] T. T. Nguyen, T. T. Nguyen, A. V. Truong, Q. T. Nguyen, and T. A. Phung, "Multi-objective electric distribution network reconfiguration solution using runner-root algorithm," $A p$ plied Soft Computing, vol. 52, pp. 93-108, 2017.

[44] C. T. Su and C. S. Lee, "Network reconfiguration of distribution systems using improved mixed-integer hybrid differential evolution," Institute of Electrical and Electronics Transactions on Power Delivery, vol. 18, no. 3, pp. 1022-1027, 2003.

[45] T. T. Tran, K. H. Truong, and D. N. Vo, "Stochastic fractal search algorithm for reconfiguration of distribution networks with distributed generations," Ain Shams Engineering Journal, vol. 11, no. 2, p. 389, 2020.

[46] K. Jasthi and D. Das, "Simultaneous distribution system reconfiguration and DG sizing algorithm without load flow solution," IET Generation, Transmission \& Distribution, vol. 12, no. 6, pp. 1303-1313, 2018.

[47] N. Nikmehr and S. Najafi Ravadanegh, "Heuristic probabilistic power flow algorithm for microgrids operation and planning," IET Generation, Transmission \& Distribution, vol. 9, no. 11, pp. 985-995, 2015.

[48] N. Nikmehr and S. Najafi Ravadanegh, "Reliability evaluation of multi-microgrids considering optimal operation of small scale energy zones under load-generation uncertainties," International Journal of Electrical Power \& Energy Systems, vol. 78, pp. 80-87, 2016.

[49] Y. M. Atwa and E. F. El-Saadany, "Probabilistic approach for optimal allocation of wind-based distributed generation in distribution systems," IET Renewable Power Generation, vol. 5, no. 1, pp. 79-88, 2011.

[50] M. Sedighizadeh, M. Esmaili, A. Jamshidi, and M. -H. Ghaderi, "Stochastic multi-objective economic-environmental energy and reserve scheduling of microgrids considering battery energy storage system," International Journal of Electrical Power \& Energy Systems, vol. 106, pp. 1-16, 2019.

[51] Z. Yue, Y. Liu, Y. Yu, and J. Zhao, "Probabilistic transient stability assessment of power system considering wind power uncertainties and correlations," International Journal of Electrical Power \& Energy Systems, vol. 117, Article ID 105649, 2020.

[52] F. Hu, K. J. Hughes, D. B. Ingham, L. Ma, and M. Pourkashanian, "Dynamic economic and emission dispatch model considering wind power under Energy Market Reform: a case study," International Journal of Electrical Power \& Energy Systems, vol. 110, pp. 184-196, 2019.

[53] A. Zakariazadeh, S. Jadid, and P. Siano, "Economic-environmental energy and reserve scheduling of smart distribution systems: a multiobjective mathematical programming approach," Energy Conversion and Management, vol. 78, pp. 151164, 2014. 